\title{
Facade renovation - replacement and restoration of the panels in a monument protected object
}

\author{
Michal Novotný ${ }^{1, *}$, and Barbora Nečasová ${ }^{1}$ \\ ${ }^{1}$ Brno University of technology, Faculty of civil engineering, Institute of Technology, mechanization \\ and construction management, Veveř́ 331/95, Brno, 60200, Czech republic
}

\begin{abstract}
The article deals with problems of reconstruction of the facade and the associated problem of replacement or repair of the panels. In conventional buildings it is a smooth operation, but it is problematic in monument-protected objects. In the case of a common building, it is possible to choose any modern panels and simply replace them, but for historical objects we have to follow the claims and the rules of monument protection. In practice, it usually means the impossibility of use of modern panels, but at least a combination of old and modern technologies. Another possible solution to the problem is renovation, or repairs to the original state of the existing panels, of course with respect to the functionality of panels. The implementation of such repairs must always be based on the technical and historical survey of the condition of the object and the repairs must be professionally designed. Subsequently, corrections are made, during which it is necessary to pay particular attention to observance of the technological procedures, rules and instructions particularly in terms of monument protection. However, the functionality of the works or elements made with regard to the quality of the environment within the building is not negligible. A common problem is the lack of control of technical requirements and functional requirements. Underestimation of the problems then leads to difficult repairs. The article points to the mistakes and problems of one such construction project on a historically protected chateau building.
\end{abstract}

\section{Introduction - Purposes and problems of the construction}

At the turn of March and April, our institute was approached by the director of the Jevišovice Retirement Home, located in the new chateau in Jevišovice. At the time this object was undergoing the first phase of the facade restoration and we had to make a professional assessment of the works that had been carried out with regard to their quality, timeframe and functionality. According to the director, the quality of the works was not sufficient, the technical supervision of the construction was not performed well, and some parts of the implement work differed from the project documentation. The construction was also delayed from the original plans. Authors were entrusted to conduct local surveys and to make the assessment. This assessment can be divided into the following key points:

- Finding and exploring problems and input parameters,

- Local investigation and identified defects,

- Recommended solution.

\footnotetext{
* Corresponding author: novotny.m1@seznam.cz
} 


\section{Finding and exploring problems and input parameters}

Our investigation related to the new chateau in Jevišovice, which, together with the castle park, is included in the list of cultural monuments. Due to this fact, the repairs and renovations are handled in cooperation with the Monument Office. Therefore, one part of the project documentation was a restoration project, but also granulometric measurements, a record of the facade elements, a static assessment, and also a technical report describing the demolition and reconstruction works. This documentation was provided to us for review, and some of its necessary parts were also provided to us in electronic form. At the same time, we were provided with records of the inspections, and additions to the contract for work between the ordering party and the contractor (the contract itself is confidential until the end of the project). The overall intention was to restore the facade of the new tower, repair the worst damaged parts of the adjoining facades, and to replace or refurbish the doors and windows on these facades. The director of the retirement home, as the representative of the client, raised the following questions during the opening meeting:

- Is the scope of the work already implemented in accordance with the documentation and the contract for work?

- Is the quality of work in accordance with the applicable laws, standards, documentation and contract for work?

- Were any defects and failures found during the inspections and the local survey, which are not in accordance with the required state of implemented work according to the documentation and the contract for work?

- Were any defects been found, which strictly prevent the handover of the work? (This was linked to the completion deadline and the handover of the work.)

Based on these questions and communicated facts a local investigation was carried out, which focused mainly on functional and fundamental defects of the work. The professional commission's objective was to answer the above mentioned questions. In the first phase of the background and documentation survey, a time schedule for corrections was found, which contained delays due to climatic conditions and consequent failure to meet deadlines. Furthermore, insufficient definition of the conditions to make a decision whether to replace or repair the panels was found - even though in this situation the decision should be made based on the documentation with a list of joinery elements, in which it was determined whether there should be an exchange or a repair. On the basis of the inspections and records, a settlement agreement was found, which read that several elements were to be repaired instead of replaced. Another finding was the inadequate definition of the work of the technical supervisor, whose duties were determined only in a framework. The next step was the local investigation and record of the detected defects.

\section{Local investigation}

Our local investigation was conducted three times, with time gaps, so that the contractor could correct any defects and errors. The dates were set at 5/4/2017, 19/4/2017 and 24/4/2017. Based on the first investigation, basic mistakes were identified and the director, who is also the client, was recommended several steps to take as a remedy. Also, the deadlines allowed the executive company to correct its mistakes. The measuring devices used were: a measuring wedge, a tapemeasure, and a camera. Laboratory tests and examinations were not required.

The basic errors found were:

- surface defects of the repaired parts - on the facade and panels - dirt, scratches, residual paints, mortars and adhesives, uneven coloring, unfinished coatings (fig. 1a), missing sealing, surface damage etc.

- incomplete or not started repairs of the elements (fig. 1b), missing elements such as railing, tiling of ledges, and roof entrance, 

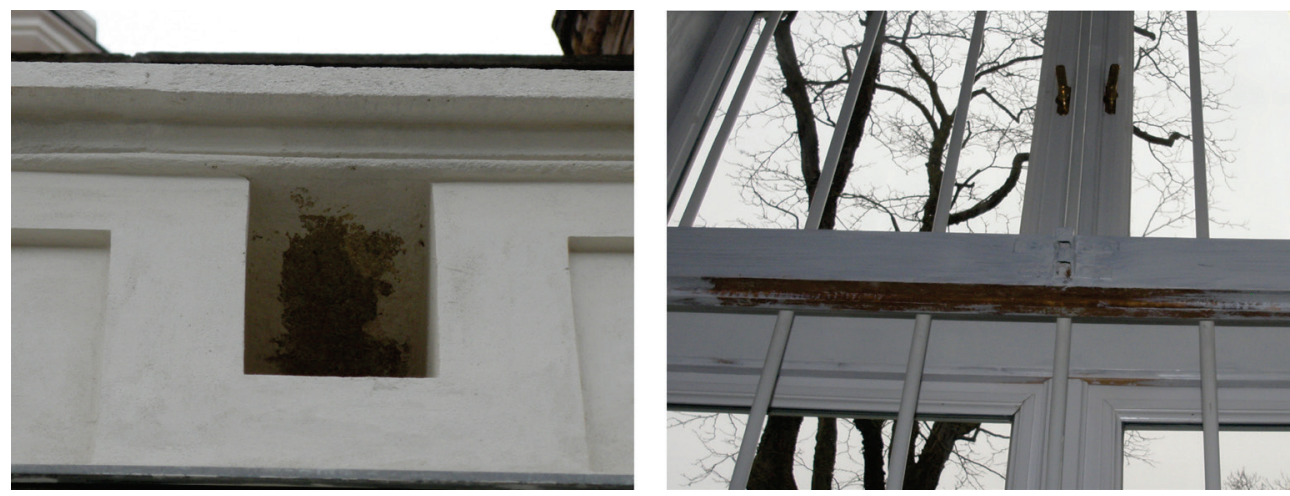

Fig. 1. Aesthetic defects: 1a - Left - incomplete facade surface, 1b - right - unfinished window frame coatings [1].

- mechanical problems of the functionality of the panels - impermanence (large gap between wings and frame - up to $5 \mathrm{~mm}$ joints - fig. 2b) and crossed or hinged casements, failure of the fitting or its absence (fig. 2a), crossing of the casement in the frame, missing seals,

- aesthetic defects - imperfections of paintings - different shades, splashes of paints and other materials on final surfaces, scratched glasses, paintings, etc.
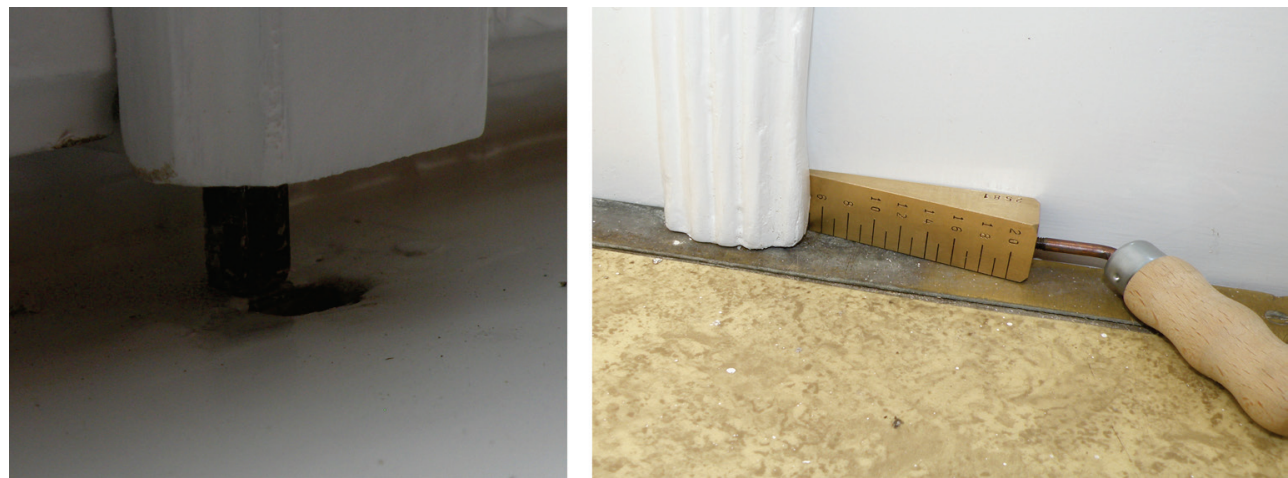

Fig. 2. Functional defect - 2a - left - inoperative window fitting, $\mathbf{2 b}$ - right - large gap between the wings of the exterior door - measured by the measuring wedge - gap of approx. $6 \mathrm{~mm}$, [1].

Our local survey focused mainly on the functional defects and unfinished work in order to answer the questions - connection with the handover and completion of the construction. These were summarized in the list and made available to the client. As part of the control investigations in the next two dates, some defects have been rectified and most of the missing elements have been added. The remaining problems to solve for the client, the site manager, and the contractor were mainly the defects connected to the function of the panels, especially the windows. These were mainly flaws in the panel's functionality - i.e. tightness, mechanical fitting, opening and closing, safety and visual appearance of the surfaces.

\section{Standard and law requirements}

The assessment of the problems was carried out mainly with regard to the applicable Building Act and related binding decrees, laws and standards. Unfortunately, this topic was not specified in the documentation, so the customer was in a difficult position to negotiate with the contractor. Especially the aesthetic problems and problems with the functionality of the panels were not captured. Subsequently, when assessing the state of the object and forming the expert opinion a 
special attention was paid to the client's requirement on the functionality and usability of the repaired parts, and also the visual appearance of the panels and facades. Above all we evaluated the mechanical functionality of the elements - closure, fittings, tightness of the casements in the frames, the shape and design of the panels, the finishing, and the overall condition of the casement. At the facade we observed primarily the finishing surfaces and the extent of repairs according to the documentation. The recommended solutions were in accordance with the requirements of laws and standards.

Following the Building Act 183/2006 [2] and its amendment 350/2012 [3], the decree 268/2009 Coll. about Technical Requirements for Buildings [4], specifies in Section 8 the essential requirements for the protection of health of persons and animals, healthy living conditions and the environment, protection against noise, and energy saving and thermal protection. These requirements, however, are not compatible with the poorly functioning or leaky windows. Section 10 - General Requirements for the Protection of Health, Healthy Living and the Environment - states that the building and its components must be designed and constructed in such a way as not to endanger the people by the consequences of insufficient thermal and sound insulation properties of the structures and its components. Because this is a home of retired people with permanent and temporary residence here, the thermal and noise conditions are paramount. It is also closely related to Section 16 of the Decree, which deals with energy saving and thermal protection, which states that the construction must guarantee the thermal comfort, required thermal parameters of the structure, thermal moisture conditions (leaky windows $=$ draft, large heat losses) and low energy consumption of the building (to its possible extend it is a historic building). Section 26 deals with the properties of the panels, and it is important to mention that "The construction of the apertures must be of sufficient stiffness that no collapse, hanging or other deformation occurs during normal operation and must withstand the load including its own weight and wind load even when the casement is open, without damaging, shifting, distorting or worsening the function." This means that the problems with the casements crossing, unattached frames and large spaces between casements and window frames are inadmissible. However, some problems can be solved by means of seals and additional structures. Parameters of air permeability and thermal parameters are set by standards. Standards also define the shapes and tolerances of the panels during the installation as well as the quality of their fabrication.

In the assessment of the state of the structures and the panels - especially the windows we derived mainly from the standards (Czech Technical Standard - hereinafter CTS) 746101 for Wooden Windows - basic specification [5], and CTS 746077 for Windows and External Doors - installation requirements [6].

The standard CTS 746101 for Wooden Windows states the following facts - point 8 Appearance and Finishing - "Wooden windows must be built with a complete surface finishing applied on all surfaces after assembly and before glazing, including surfaces, which become hidden after assembly. The appearance of the surface treatment is judged from a distance of $1 \mathrm{~m}$ and compared to a reference sample. The degree of gloss and color shade must be uniform throughout the surface and correspond to the paint used. Surface treatment of wood must cover its entire surface, scratches and similar damage must be repaired. Final surface treatment must be continuous without surface defects.

Surface defects are not considered to be:

- a slight trace of the characteristics of the technology used for the surface treatment with the use of paints, and marks caused by wood grinding with sandpaper higher than No. 80;

- visible relief of wood texture, especially with the use of water-borne paints;

- color difference of surface depending on wood texture (spring and summer wood) and color difference of surface depending on wood absorption; 
- allowed are hair cracks on the coat in the corner joints of the frames and casements but they can only reach a maximum of 1 according to CTS EN ISO 4628-4 [7] - i.e. very small with a size visible only at magnification (according to the above standard, up to size of $0.2 \mathrm{~mm}$ );

- it is allowed to mechanically secure the components of the panels such as glazing strips, cover rails, etc.

- allowed are hair cracks in the vicinity of fasteners (for example fittings) that are not subjected to direct weathering."

Point 9 - Installation - specifies the variance tolerance, for us were important the values of the rectangular dimensions of the frames: the difference in diagonal lengths, which is $3 \mathrm{~mm}$ for windows up to $1800 \mathrm{~mm}$, and $5 \mathrm{~mm}$ for windows up to $3000 \mathrm{~mm}$. The gap between the contact surfaces of the casements and the frames, and the frames with respect to each other, is permitted at the maximum value of $2 \mathrm{~mm}$ - which can be considered difficult to repair, and therefore, an additional solution is needed, for example by sealing.

In terms of the standard CTS 746077 for Windows and External Doors - Requirements for Installation [6] was important part no. 4 Design Requirements, subpart 4.3 Construction Opening, which reads: "Built-in windows and external doors must not impair their performance or become a health and safety risk for people. The maximum permissible deviation of the rectangularity of the frame profile (deflection of the frame profile to the longitudinal axis) of the embedded product is $3 \mathrm{~mm}$ for length and width up to $2000 \mathrm{~mm}$ (inclusive), and $5 \mathrm{~mm}$ for length and width over $2000 \mathrm{~mm}$. The maximum permissible deviation of the vertical and horizontal dimensions of the frame of the embedded product of size up to $3,000 \mathrm{~mm}$ (inclusive) is $2 \mathrm{~mm}$ per meter, but overall maximum of $3 \mathrm{~mm}$. In the case of strip windows assembled from individual frames that are reinforced, the tolerances apply to individual frames. The maximum tolerance for the rectangular dimensions of the frames is $3 \mathrm{~mm}$ for windows and doors up to width of $1500 \mathrm{~mm}$ and height of $2200 \mathrm{~mm}$ (inclusive) and $5 \mathrm{~mm}$ for windows and doors of width of $1500 \mathrm{~mm}$ and height of more than $2200 \mathrm{~mm}$ and less than $3000 \mathrm{~mm}$ ".

In terms of control during the installation of the elements, it is important to check the following points:

- design and properties of the panels, vertical and horizontal installation, rectangularity;

- anchoring the product to the aperture and making the connecting joint before it's covered

- opening and closing function of the moving casements;

- appearance of the product regarding possible defects and damage.

A record in form of a transfer protocol is made, which states the progress and completion of the work. So much to the background in terms of standards and laws. Unfortunately, there are not many legal documents, which deal with the finishing or the installation of the panels. There are more standards, but they are not binding unless they are required by the contract of work.

\section{Conclusion - summary and recommended solutions}

After evaluating the findings and assessing the problems resulting from the local investigation, various repairs were recommended - for instance - the removal of defects and faults during the subsequent construction works. Unfortunately, some of the defects were not of a character to be repaired - it was recommended to replace the concerned panels. This, however, mainly concerned the repairs not yet implemented. On the basis of all the facts, the following conclusions can be drawn:

- the need for high-quality documentation with clearly defined responsibilities of the participants, with specific workflow plans including details, precise steps and procedures, and the specification of the working hours of the contractor or the site manager,

- the need for a detailed contract of work (hereinafter $\mathrm{CoW}$ ) with precise obligations and requirements for the individual participants in the process, including a description of their activities - i.e. no subsequent works cannot be required, if they do not form part 
of the contract - e.g. the technical supervisor was not obliged to check the aesthetic parameters of the panels or the façade,

- clearly define the parameters of repaired structures - either renovation, replacement or repair of elements - not to change these parameters during the construction based on unilateral decision and, in case of uncertainty of the state of the construction or a problem solution, consult an impartial expert,

- document immediately any delay in construction or problems arising during construction by photographs or records - e.g. non-standard temperature conditions, non-observance of working hours - influence on later assessment in case of failure to observe CoW terms, - ensuring a high-quality site manager and writing a detailed contract, defining his duties, especially if there is a requirement for control beyond the applicable standards and laws e.g. the aesthetic aspect of the panels,

- insist on detailed element controls - especially when it comes to their functionality and quality swift checks may not reveal, for example, unattached window casements, inoperative fittings or hanging casements (cannot be detected without measurement),

- not to accept the work with the promise of completing it after the handover or after the deadline - strictly insist on observance of the contractual conditions - i.e. the necessity of good contract of work.

Clearly, the assessment implies the need for quality documents, contracts and, above all, for clearly defined obligations of the participants, especially the site manager. Any failure to comply with the qualitative requirements will result in problems with the usage and warranty or post-warranty repairs.

Outputs and defects detected will also be used to adapt the working methods and test procedures for new facade technologies, which are addressed in grants from the Institute of Technology, Mechanization and Building Management at the Faculty of Civil Engineering with numbers FAST-S-17-4329 and FAST-S-17-4255.

\section{References}

1. Author's archive. On site photographs. Jevišovice (April 2017)

2. Act no. 183/2006 Coll. on land-use planning and building regulations (Building Act). (Collection of Law. Prague, 2006).

3. Act no. 350/2012 Coll., amending Act no. 183/2006 Coll., on spatial planning and building regulations (Building act), as amended, and certain related acts (Collection of Law, Prague, 2012).

4. The decree no. 268/2009 Coll. about technical requirements for buildings (Collection of Law, Prague, 2009)

5. ČSN 746101 Wooden windows - basic regulations (The office for standardization, metrology and testing, Prague, 2015)

6. $\check{C} S N 746077$ Windows and exterior doors - Installation requirements (The office for standardization, metrology and testing, Prague, 2014)

7. ČSN EN ISO 4628-1 Paints and varnishes - Evaluation of degradation of coatings Designation of quantity and size of defects, and of intensity of uniform changes in appearance - Part 1: General introduction and designation system (The office for standardization, metrology and testing, Prague, 2016) 